\title{
SCARLET FEVER EXPERIENCES.*
}

BX R. H. TROTTER,

Medical Officer of Health, Holmfirth.

F XTRAORDINARY events in a small and restricted field of observation may well be matters of everyday occurrence with men whose public health outlook is, by the very nature of their position, necessarily wider, and the cases I here bring forward have also in part rather a clinical than a public health interest, being the experiences of a Medical Officer of Health who is also a general practitioner; but this dual capacity has enabled many cases to be followed personally throughout their course, and they are, after all, brought forward rather as suggestive than as material upon which to found dogmatic views on the epidemiology of scarlatina.

The urban districts of Holme, Holmfirth, Honley, and Netherthong (combined for the purpose of the Medical Officer of Health appointment) contained at the census of 1901 a population of about 15,000 . They lie in the extreme north-west corner of the West Riding, and possibly their comparative immunity from serious epidemics is in part incidental to their somewhat isolated position. Though all urban districts, over considerable portions of their area at all events they have a semi-rural character.

Compulsory notification has been in force over the whole area since May, 1899, and up to the end of November, 1906, 274 cases of scarlet fever have been notified, with only three deaths. In fact, so mild and clinically unimportant has the disease been during the last ten years, that one has come to look upon it rather as a cause of unpleasantness between parents and parents, and between parents and the officials of the Sanitary Authority, than as a dangerous infectious ailment. We have had an isolation hospital since August, 1904, and now fully three-fourths of the scarlatina cases are removed thither.

Such is a brief account of the local conditions under which the cases occurred, and for the sake of order these cases are grouped under different heads.

I.-Prolonged vitality of infection in imperfectly disinfected houses. -Several cases illustrate this, the following especially :-

(1) B. M., notified September 19th, 1900. Pre-hospital days, therefore kept at home. The house had only two bedrooms, and individual isolation was impossible, but there was no other dwelling

\footnotetext{
* Read at Meeting of Yorkshire Branch, 14th December, 1906.
} 
within a quarter of a mile. Brother, A. M., notified September 28 th. On September 25th, mother, who had previously had scarlet fever. developed typical scarlatinal throat, but had neither rash nor subsequent desquamation. On October 5th another brother, H. M. . was notified. As mother only was available as nurse, the whol: house was freely exposed to infection. At the termination of the cases the dwelling was cleaned throughout, but no other disinfection was possible. On June 15 th, 1901, a cousin, aged 6, came to live here: he was one of a family of eight children, none of whom had scarlet. fever at the time, or subsequently developed it, and he came from a neighbouring sanitary district where there were no cases of scarlet fever; he was driven over in a cart some eight or ten miles by the father of the previous cases. On June 18th he developed scarlet. fever. Of course there is no denying the possibility of infection from another source, but careful enquiry rendered it extremely improbable, and I think this child was infected in the home of the earlier cases eight months after they had apparently ceased to be infectious. I may add that none of these earlier cases had any of those complications which are supposed to render the infectious period unusually prolonged.

(2) In the next case the intervening period is much shorter, but the death of the first patient removed all possibility of personal inter-infection. E. L., notified July 30th. Died August 6th. The bedroom was "stoved" with sulphur, and cleansing carried out under the supervision of the inspector of nuisances. Five weeks later the child's sister, who had in the meantime certainly not been exposed to any other infection, developed scarlet fever.

(3) This case I quote as curious, though the distance of time between the first and second cases seems to make any connection between the two almost impossible. C. B., notified September, 1901; absolutely no personal isolation, but house cleansed at end of illness. On April 11th, 1904, H. B., her brother, developed the disease, and most careful enquiry utterly failed to suggest any possible origin for his ailment save in his own home.

(4) M. B. Illness began March 26th. Careless mother; no attempt to keep child in one room. On June 11th, nearly three months later, a second case followed in the same house, for which no origin other than home infection could be discovered.

The foregoing cases were in the pre-hospital days. The following series occurred since the hospital was in use.

(5) G. R., began September 20th, 1905. Removal followed by disinfection September 22nd. R. R., his brother, who was away at, 
school, came home for the week-end September 29th. Began October 2nd. Removal and second disinfection October 4th. Three months later, January 20 th, 1906, G. R., aged 2 years, who had never been away from home nor been in contact, so far as could be discovered, with any infectious person, developed scarlet fever.

(6) J. W. S., removed October 6th. One other child. After removal of brother, house was thoroughly cleansed and disinfected by sanitary officer with sulphur; the other child, so far as my enquiries could show, was never exposed to infection outside after the brother's removal, but nine weeks later developed scarlet fever; fortunately a day or two before her brother was discharged, or she would have been labelled a return case.

In the present state of our knowledge of the epidemiology of scarlatina, it is difficult or impossible to set a term to the vitality of the infection in imperfectly disinfected houses, and as an explanation of otherwise inexplicable outbreaks such prolonged vitality seems certainly worth bearing in mind.

II.-Scarlet fever infection apparently carried by water.-On September 14th, 1900, after the occurrence of two cases of scarlet fever in a house where isolation was impossible, cleansing of the house was carried out. On the other side of the wall, against which mats, etc., were beaten, and which encloses the yard in which carpets were shaken, is an open well, the overflow from which is piped directly to a farmhouse a quarter of a mile or more away, for which it forms the only supply. On September 17 th a young man living at this farmhouse developed scarlet fever. There was no other case of scarlet fever in the district at the time, and the tenants at the farm, being newcomers, were absolutely unacquainted with the members of the recently infected household, and had never been into their house. Six days and eight days later respectively other members of the family were attacked, but of course direct infection from the first case was very possible. Very careful investigation failed to suggest any possible origin for the primary case, until the questions as to water supply in the course of the ordinary routine enquiry led me to the idea that infected water was the possible causative agent.

III.-Scarlatina with typical onset and course, but entire absence of subsequent desquamation.-Though a scarlatinal throat without rash is in my experience not uncommon, the occurrence of a scarlet fever with rash but without desquamation does not seem to be generally admitted, but the following experiences suggest that it does sometimes occur.

(1) N. R., aged 12, attending school from which several scarlet fever 
cases had recently been notified, began to be ill during night of September 20th to 21st. On the morning of September 22nd, when first seen, she had developed an extremely well-marked scarlet rash and severe throat affection of typical scarlatinal character. So severe in fact was the throat condition as to cause some anxiety, and she was seen by another medical man, who unhesitatingly concurred in the diagnosis. The ailment ran the clinical course of a moderately severe attack of scarlet fever, but though repeatedly and carefully examined, no trace of desquamation was ever observed. She was isolated at home for four weeks, and then mixed freely with the rest of the family without other cases occurring.

(2) H. W. Scarlet fever prevalent in the district. Illness began January 10th; rash and sore throat January 11th. Apparently a clear case of scarlet fever. Never desquamated.

(3) A. T. Onset February 15th; rash February 17th. Severe throat affection and well-marked rash lasting four days. Had later nasal discharge causing impetiginous-looking patch at opening of nostril, and had also prolonged cervical glandular enlargement, but never a trace of desquamation. Brother had scarlet fever, followed by usual desquamation, in same house ten months previously.

(4) S. No scarlet fever in the district, but six days before his illness began he visited a district in which the disease was prevalent. Onset with vomiting, sore throat, and scarlatinal rash. Seen by second medical man, who concurred in diagnosis. Never desquamated, but isolated at home for $3 \frac{1}{2}$ weeks.

These cases at all events illustrate that the intensity of the rash does not determine the extent of the desquamation, but the obvious reply to the diagnosis of scarlet fever without desquamation is, "Such cases are not scarlatina at all," and of course we have no means, as in the case of diphtheria, of setting doubts at rest by the identification of the specific causative agent. But in each case the clinical history was absolutely in accord with that of normal scarlet fever, save that desquamation failed to follow in the usual course. To establish my hypothesis it would be desirable to produce a case of the kind which had been an infecting agent, and though two cases which were possibly of this nature are in the registers, they are both open to fallacy. I therefore quote them rather as suggestive than in definite support of my proposition.

(1) Case of scarlet fever in an adult in a district supposed to be free from infection. Enquiry revealed the fact that her niece from a district a few miles away was staying in the village, and had had an indefinite illness (sore throat and vomiting) four and a half weeks 
before ; since she left home her brother had developed scarlet fever, and word had been sent that she was to remain away lest she might also catch it. This child was looked up and examined; she had a sore nose, with discharge from the nostril and glandular enlargement, but no desquamation, and none had been observed by friends. She had attended the village school, and an outbreak of scarlet fever in connection with the school followed, necessitating school closure and causing the death of one child.

(2) During an epidemic associated with an elementary school a nonschool-goer in an isolated group of houses some distance from the village got scarlet fever. Her elder sister was found to have been away from school fourteen days for a "cold" ; she had sore nose and enlarged glands, but no desquamation. Another child in the same group of houses who was a school-goer and had played with the baby began to be ill (scarlet fever) and developed a rash the same day as the infant did, so quite possibly she was the infecting agent, though the something like simultaneous onset is against this, and the child with the sore nose may have infected both.

Of course I am well aware that desquamation as an element in carrying infection has come to be disbelieved in. I think no one will deny its value as an aid to late diagnosis of scarlet fever: yet if my cases suggest anything they suggest that its absence is no guide at all.

In connection with this "incomplete scarlet fever" the following recent experience is interesting. Three boys living in the same yard and attending the same school began to be ill simultaneously; scarlet fever was prevalent in association with the school they attended. All three presented the same symptoms at first, viz., sore throat, vomiting, and fever. One developed a rash, and was removed to hospital; the other two, though under careful observation for some time, cleared up without any further developments, and had to be discharged for want of evidence. Eighteen days afterwards the young brother of one of these cases, who had never been away from home, developed scarlet fever.

IV.-Return Cases.-Our hospital era is not sufficiently long to have furnished many instances of these; there are only three, and one is at least doubtful as regards the precise nature of the ailment in the second case.

(1) G. F: M., began November 16th ; removed November 20th (this case was taken by a neighbouring authority, as our own hospital was not built). Six members of family unprotected by previous attack, ages 21 years to 4 years. In hospital eight weeks, had sore behind 
ear, but this absolutely well on discharge. Had two attacks of nose bleeding after the other cases began, but no nasal discharge or soreness. Twenty days after his return home, brother aged 5 and sister aged 10 began simultaneously, and thirteen days later another sister aged 8 .

(2) E. L., onset July 15th; removed July 17th; returned September 7 th. September 13 th brother aged 3 began to be suddenly ill during the night (vomiting, sore throat, heat of skin); mother, suspecting scarlet fever, looked for rash, but found none. Twelve days later, ill and fretful again, and urine bloody. Seen by doctor for first time two days later ; no trace of desquamation, but urine bloody and glands at angles of jaw much enlarged. Never isolated, made rapid recovery, and no further cases occurred. The nature of his illness must remain doubtful, but the concatenation of circumstances is certainly curious. The original patient presented no symptoms of prolonged infectiousness.

(3) N. L., rash September 13th; removed September 14th. In hospital about six weeks. No trace of nasal discharge when she came home. Few days later this began, and persisted when discovered in school, accompanied by soreness at opening of nostril. After her return she was kept in nearly a fortnight, mixing with three sisters, ages 17-26, unprotected by previous attack. On November 4th, thirteen days after return, spent the evening in company with a schoolfellow who twenty-four hours later had an attack of vomiting, diarrhcea, and sore throat (no rash seen by parents and no desquamation discoverable when medically examined later). On November 5th she went to school for the first time. On November 7 th and November 10th respectively two children in the same class were attacked. An examination of the school-children following the notification of these cases led to the discovery of N. L.'s condition, and a further exclusion from school.

$\mathrm{V}$.- The following cases illustrate the low infecting power of scarlet fever when apparently circumstances were eminently favourable for a rapid spread of the disease. In each case isolation may be fairly described as non-existent, yet no further cases followed.

(1) H. H., five house-mates, not had it, ages 9 to 23 years; only two small bed-rooms. No further cases.

(2) T. H, two other children, ages 4 and 3, unprotected by previous attack; mixed freely with patient, but escaped.

(3) T. M., two unprotected house-mates, ages $3 \frac{1}{2}$ and 2 , no isolation, but they escaped.

(4) M. R., six, not had disease, ages 11 to 21 , one bed-room divided into three cubicles. No further cases. 
(5) C. K., six, not had disease, ages 10 to 24 , no isolation. No further cases.

(6) H. A., six weeks after illness began returned to school still desquamating and wearing the undisinfected clothes worn during whole convalescence. Discovered after attending half-day. No outbreak followed.

(7) E. T., rash May 24th; at home a day or two, then attended large elementary school until June 6th. No further cases.

(8) A. B. and sister; seven others in house, ages 5 to 23 , not nad scarlet fever. Fourteen days after illness began returned to school and mixed freely with other children. Discovered in school fourteen days later, A. B. still desquamating freely. No outbreak followed.

These cases certainly suggest that remarkable escapes from epidemics, due to the eccentricity of the disease, must have frequently occurred in the days

"When wild at home the ignoble scarlets ran,"

escapes which a later generation is wont to attribute, with pardonable pride, to its magnificently equipped isolation hospitals.

VI.-Unfortunately, as is of course well known, the converse is at times equally true, that is, scarlet fever can be contracted after an extremely short exposure, and can be carried a long distance in clothing and other articles. I have found in the registers several striking instances of these facts.

(1) G. O. One other case of scarlet fever in the district. The father of this case came to see the mother of $G .0$., who was secretary of the District Nursing Committee (not herself a nurse); he sat twenty minutes in a chair, which was occupied by G. 0 . immediately after he left; five days later she developed the disease, though there was absolutely no history of any other exposure to infection.

(2) Two cases of scarlet fever in isolated group of houses (cases in one house). It appeared that just before they began a relative who lodged in a house from which cases had recently been removed, but himself quite well, had come home for the week-end, walking six miles to do so.

(3) A. T. Person from infected house walked three-quarters of a mile to fetch this child's night-suit as a pattern; mother of A. T. gave it to her, and then hearing that she had a sick child (case then not diagnosed) called her back when she had gone a few yards and took night-dress back. A. T. developed scarlet fever three days later, though no other exposure could be traced.

(4) E. J. Rash January 31st. No cases in this part of district, 
but enquiry revealed that uncle, whose child began to be ill with scarlatina on January 28 th, had walked over to see E. J. (two miles) the same day. There had been no other communication between the families.

(5) Mrs. T. M. literally nursed her infant aged $2 \frac{3}{4}$ years through an attack of scarlet fever in January, 1903. In January, 1906, went into an infected house, but hearing of case here did not sit down, and remained a few minutes only. Went home panic-stricken, and thirtysix hours later developed severe scarlet fever.

(6) Five persons in house, one a baby. First case April 12th, kept at home. No further cases until May 1st, but between 1st and 9th all the rest of the family, save the baby, were attacked.

It is a common practice with the artisan classes in our district to increase the bed-clothes by the addition of overcoats and other articles of clothing in daily use. If an overcoat lies during the night on the bed of a scarlet-fever patient and during the day being worn by the father on his way to and from work, hangs close beside or upon the coat of a fellow worker, it may readily become a carrier of infection. The following case may possibly be accounted for in this way.

(7) A. A. H. lives in isolated village, no other cases of scarlet fever in district and not been away nor had any visitors. Father, however, works in a mill in another district two miles away, where scarlet fever is epidemic.

In concluding my paper I must again confess that extensive opportunities for observation are essential for the collection of materials which may bring us nearer to the solution of the many problems which scarlet fever presents, for it is of all infectious disorders the most prone to vagaries at present inexplicable.

\section{IS SCARLET FEVER LESS PREVALENT AS WELL AS LESS} FATAL THAN FORMERLY ? *

BY J. C. MCVAIL, M.D., D.P.H.

Medical Officer of Health of Stirlingshire.

HE lowering of a death-rate from a given disease may depend
either on diminished prevalence of the disease, or on diminished
fatality, or on both. Now, in enteric fever it is known that the
fatality-rate, that is, the number of deaths per 100 attacks of the
disease, is practically unchanged. The type of enteric fever from
which the country suffers now seems practically identical in its severity

* From Annnal Report, 1906. 